\section{A Biologically Inspired Organometallic Fuel Cell (OMFC) that Converts Renewable Alcohols into Energy and Chemicals}

S. P. Annen, V. Bambagioni, M. Bevilacqua, J. Filippi, A. Marchionni, W. Oberhauser, H. Schönberg, F. Vizza*, C. Bianchini*, and H. Grützmacher*, Angew. Chem. Int. Ed. 2010, 49, 7229.

ETH Zürich and ICCOM-CNR, Polo Scientifico Area CNR (IT) Fuel cells that convert alcohols into electrical energy and the corresponding carboxylate product could be used as power sources for biomedical applications. The authors report a new type of fuel cell which efficiently converts ethanol to acetate: the anode consists of a bifunctional organometallic complex deposited onto a conductive carbon support. This organometallic fuel cell, although unoptimized, has a power output comparable to conventional fuel cells based on noble metal nanoparticles.

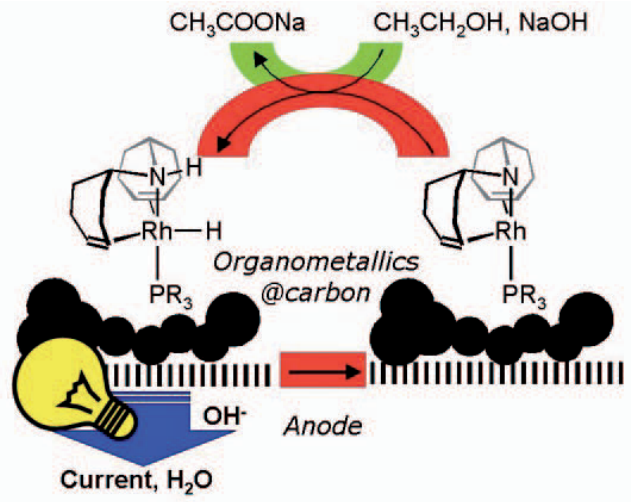

\section{A Coordination Cage with an Adaptable Cavity Size}

S. Mirtschin, A. Slabon-Turski, R. Scopelliti, A. H. Velders, and K. Severin*, J. Am. Chem. Soc. 2010, 132, 14004.

EPF Lausanne and University of Twente (NL)

The authors report on a hexanuclear coordination cage that can adopt two distinct structures: a compressed structure with no internal cavity and an elongated structure. This latter can accommodate two coronene molecules $\left(V \approx 500 \AA^{3}\right)$. Importantly, the modulation of the cavity size is achieved by a conformational change that is enabled by the use of flexible connections between the metal atoms and the ligands. The results demonstrate that it is possible to construct highly adaptive coordination cages with appropriately designed building blocks.

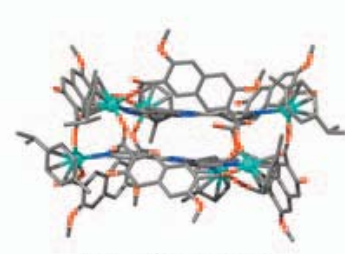

Collapsed Cage

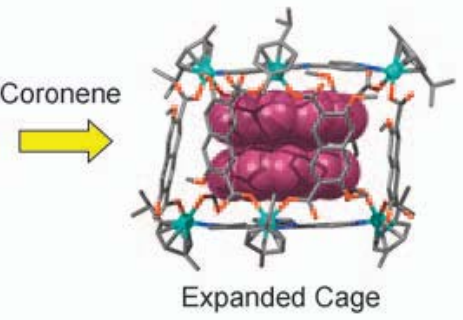

\section{Significant Variation of the Singlet-Quintet Intersystem Crossing Rate Constant in an Iron(II) High-Spin Complex as a Function of Temperature}

I. Krivokapic, P. Chakraborty, R. Bronisz, C. Enachescu, and A. Hauser*, Angew. Chem. Int. Ed. 2010, 49, 8509.

Universities of Geneva, Wroclaw (P) and Iasi (RO)

The range over which most physical quantities can vary as a function of external parameters, that is, pressure, temperature etc., is usually limited to a few orders of magnitude. Here, the authors show that the rate of intersystem crossing for the iron(II) complex in the diluted $\left[\mathrm{Zn}_{1-\mathrm{x}} \mathrm{Fe}_{\mathrm{x}}(\mathrm{bbtr})_{3}\right]\left(\mathrm{ClO}_{4}\right)_{2}$ (bbtr $=1,4-\operatorname{di}(1,2,3-$ triazole-1-yl)butane) system varies over 14 orders of magnitude as a function of temperature.

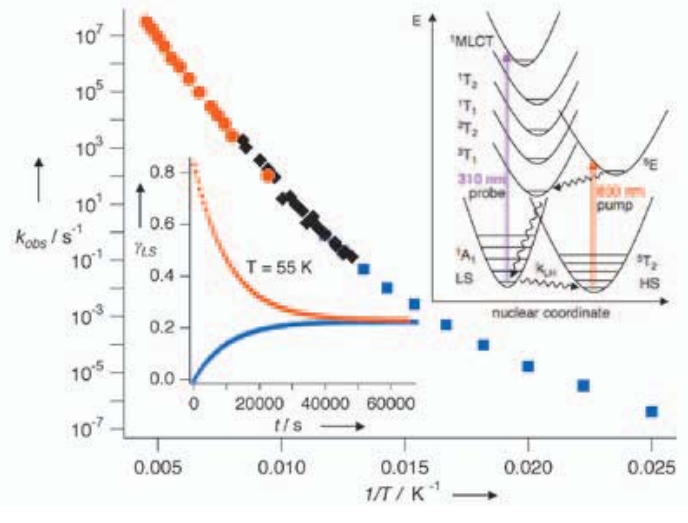

\section{Getting Ring-Closing Metathesis off the Bench: Reaction-Reactor Matching Transforms Metathesis Efficiency in the Assembly of Large Rings}

S. Monfette, M. Eyholzer, D. M. Roberge*, and D. E. Fogg*, Chem. Eur. J. 2010, 16, 11720.

University of Ottawa (CDN) and Lonza Ltd., Visp

While ring-closing metathesis revolutionized laboratory synthesis, industrial applications in the synthesis of large rings remain scarce, even for high-value targets, due to prohibitively high costs associated with the high catalyst loadings usually required. In an evaluation study of different reactor designs, it was shown that the catalyst loading can be reduced 25 -fold (down to $0.2 \mathrm{~mol} \%$ ) in a continuous stirred-tank reactor when compared to a batch reactor, while maintaining perfect selectivity in the conversion of a precursor of an important macrocyclic perfumery agent.

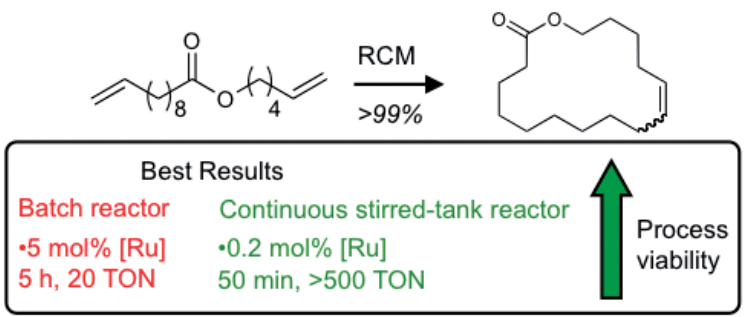

